\title{
Evaluation of the implementation of a state government community design policy aimed at increasing local walking: Design issues and baseline results from RESIDE, Perth Western Australia
}

\author{
Billie Giles-Corti ${ }^{\mathrm{a}, *}$, Matthew Knuiman ${ }^{\mathrm{a}}$, Anna Timperio ${ }^{\mathrm{b}}$, Kimberly Van Niel ${ }^{\mathrm{c}}$, \\ Terri J. Pikora ${ }^{\mathrm{a}}$, Fiona C.L. Bull ${ }^{\mathrm{a}, \mathrm{d}}$, Trevor Shilton $^{\mathrm{e}}$, Max Bulsara ${ }^{\mathrm{a}}$

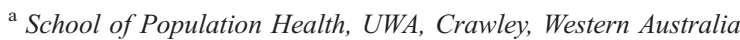 \\ ${ }^{\mathrm{b}}$ School of Exercise and Nutrition Sciences, Deakin University, Burwood, Victoria, Australia \\ ' School of Earth and Geographical Sciences, UWA, Crawley, Western Australia \\ ${ }^{\mathrm{d}}$ School of Sport and Exercise Science, Loughborough University, Loughborough, UK \\ ${ }^{\mathrm{e}}$ National Heart Foundation, Subiaco, Western Australia
}

Available online 11 August 2007

\begin{abstract}
Objectives. To describe the design and baseline results of an evaluation of the Western Australian government's pedestrian-friendly subdivision design code (Liveable Neighborhood (LN) Guidelines).

Methods. Baseline results (2003-2005) from a longitudinal study of people ( $n=1813)$ moving into new housing developments: 18 Liveable, 11 Hybrid and 45 Conventional (i.e., LDs, HDs and CDs respectively) are presented including usual recreational and transport-related walking undertaken within and outside the neighborhood, and 7-day pedometer steps.

Results. At baseline, more participants walked for recreation and transport within the neighborhood (52.6\%; 36.1\% respectively), than outside the neighborhood $(17.7 \% ; 13.2 \%$ respectively). Notably, only $20 \%$ of average total duration of walking (128.4 min/week (SD159.8)) was transport related and within the neighborhood. There were few differences between the groups' demographic, psychosocial and perceived neighborhood environmental characteristics, pedometer steps, or the type, amount and location of self-reported walking $(p>0.05)$. However, asked what factors influenced their choice of housing development, more participants moving into LDs reported aspects of their new neighborhood's walkability as important ( $p<0.05$ ).

Conclusions. The baseline results underscore the desirability of incorporating behavior and context-specific measures and value of longitudinal designs to enable changes in behavior, attitudes, and urban form to be monitored, while adjusting for baseline residential location preferences. (C) 2007 Elsevier Inc. All rights reserved.
\end{abstract}

Keywords: Environment; Neighborhood; Walking; Physical activity measurement; Urban design; Longitudinal

\section{Introduction}

Sprawling patterns of uniform low-density car-oriented land development, which characterize metropolitan housing developments in Australian and US cities, have been blamed for low levels of walking, cycling and transit use, high levels of motor

\footnotetext{
* Corresponding author. School of Population Health M707, The University of Western Australia, 35 Stirling Highway, Crawley, Western Australia 6009. Fax: +61 864881199 .

E-mail address: Billie.Giles-Corti@uwa.edu.au (B. Giles-Corti).

URL: http://populationhealth.uwa.edu.au/reside (B. Giles-Corti).
}

vehicle dependency and increasing levels of obesity (Frank et al., 2003). Urban sprawl developments not only impair human health by decreasing physical activity, and increasing obesity and respiratory problems, but also produce poor environmental outcomes (e.g., increased driving and greenhouse gas emissions and poor air quality) (Ewing et al., 2003; Frank et al., 2003).

A range of alternative housing developments have emerged to counter urban sprawl and encourage travel by active modes including Transit Oriented Developments, developments designed using New Urbanist principles, Smart Growth and Less Automobile Dependent Urban Form (Krizek, 2003). These developments are based on the premise that residents 
of pedestrian-friendly neighborhoods with higher residential density, mixed land use, and accessible shops and transit are more likely to use non-motorized forms of transport than those living in conventional suburbs poorly served with these characteristics (Ewing et al., 2003; Frank et al., 2003; Krizek, 2003). Land use has been identified by some US government agencies as a tool for producing environmental outcomes (Handy et al., 2005).

Perth, Western Australia, is one of the least densely populated cities globally, with car dependencies that rival those in the US (Newman and Kenworthy, 1989). In 1998, the Western Australian state government began trying a new subdivision design code (the 'Liveable Neighborhood (LN) Guidelines') (Western Australian Planning Commission, 2000). Based on new urbanism principles (Hall and Porterfield, 2000), these Guidelines incorporate four design elements (i.e., community design, movement network, lot layout and public parkland) intended to create safe, convenient pedestrian-friendly neighborhoods with access to shops, transit and parkland which encourage more walking, cycling and transit use. The LN Guideline trial provided a unique opportunity for a natural experiment of the impact of a new state government policy on local residents and in 2003, the Residential Environments Project (RESIDE) commenced with this aim.

There is a dearth of longitudinal evidence on the impact of urban form on walking and cycling (Ewing et al., 2003; Jackson, 2003). Although causality cannot be implied, crosssectional studies repeatedly show that residents in more walkable neighborhoods do more transportation-related physical activity, particularly walking (Transportation Research Board, 2005). However, issues of self-selection cannot be ruled out as an explanation for these results (i.e., people preferring active modes of transport or who wish to walk to local facilities simply choose to live in more walkable locations). Skeptics argue that travel preferences shape decisions about residential location rather than vice versa (Krizek, 2003). The broader question of whether urban form influences transportation choices irrespective of travel preferences remains unanswered.

Two longitudinal studies of the impact of urban form on behavior have been undertaken (Handy et al., 2005; Krizek, 2000). The first, a transportation panel study, examined changes in travel behavior in a subset $(n=550)$ of participants who moved during the course of the study (Krizek, 2000). Most participants moved into neighborhoods with similar levels of walkability to their baseline address, however $17.4 \%$ moved into more walkable neighborhoods. While moving to more walkable neighborhoods decreased distances and time spent traveling, it had very modest and non-significant impacts on the uptake of alternative modes of transport (Krizek, 2000). The author concluded that attitudes towards travel were predetermined and that 'there is little that urban form can offer as far as providing alternatives for unwilling households to not drive' (Krizek, 2003). Nevertheless, this study was relatively small and did not adjust for attitudes, lifestyle or lifestyle preferences.

Handy et al. (2005) addressed concerns raised about study design and measurement limitations (Bagley and Mokhtarian, 2002; Handy and Clifton, 2001; Schwanen and Mokhtarian,
2005) by adopting a 'quasi-longitudinal' design that retrospectively measured self-reported past and current travel behavior and travel-related attitudes of 1682 residents who moved into eight Northern Californian neighborhoods. They found support for a causal relationship between urban form and travel choices, after adjustment for attitudes and preferences. Importantly, they found evidence for potential spurious conclusions to be drawn from cross-sectional study designs.

This paper aims to contribute to the methodological literature by describing the design and baseline characteristics of participants in a quasi-experimental longitudinal study of people moving into new neighborhoods, some designed according to the LN Guidelines. The study has a number of unique features. It (1) involves a natural experiment evaluating the impact of a state government planning intervention; (2) examines whether housing development choice is associated with baseline attitudes, preferred lifestyle and behavior enabling predisposition for active transportation on subsequent behavior to be studied; and (3) uses a behavioral instrument that differentiates between transport and recreational walking undertaken within and outside the neighborhood (Giles-Corti et al., 2006). Although few other studies make this distinction (Humpel et al., 2004b), it has been argued that increased specificity may improve the predictive capacity of ecological studies (GilesCorti et al., 2005; Humpel et al., 2004a,b). In addition, as the LN Guidelines seek to change local walking behavior, differentiating between the type and location of walking is important. We hypothesized that those proposing to move into LDs will undertake more walking at baseline and be more predisposed to walk than those moving into other types of housing developments.

\section{Methods}

RESIDE uses a quasi-experimental 5-year longitudinal design. It involves people $(n=1813)$ moving into 74 new housing developments in Perth, Western Australia, some of which met the LN Guidelines. The study protocols were approved by the Human Research Ethics Committee at The University of Western Australia.

\section{Selection of housing developments}

All structure plans for new housing developments in Western Australia are approved by the state government's Department for Planning and Infrastructure (DPI). RESIDE included 18 developments classified by DPI as 'Liveable' (LDs), 11 as 'Hybrid' (i.e., those identified as having many, but not all of the LN elements) and 45 Conventional housing developments (i.e., LDs, HDs and CDs respectively). All LDs and HDs that sold land for housing during the recruitment period were included in the study. CDs outnumbered LDs and HDs, thus attempts were made to match these to the LDs and HDs using three criteria: stage of development, lot values and proximity to the ocean. If there was more than one eligible for inclusion, it was randomly selected.

\section{Selection of participants}

Participants were recruited in waves every 6 months from September 2003 to March 2005. One person from each household was selected randomly. The Water Corporation, the state water supply agency, wrote to all its customers building houses in the study areas $(n=10,193)$ inviting their participation and requesting return of a reply-paid card if they were ineligible or did not want to be contacted by the study team. Eligibility requirements included proficiency in English, $\geq 18$ years, plans to move into the new house by December 2005 and willingness to complete 
surveys and wear a pedometer for a week on three separate occasions over 4 years. The names and addresses of people who did not return the card within 10-14 days were matched to the electronic white pages and telephoned by trained interviewers who screened participants $(n=5286)$ for eligibility. A written invitation was sent to those who could not be contacted by telephone after six follow-up calls or if no telephone contact details were available $(n=3862)$. Three follow-up letters were sent. All participants received written information about the study and provided written consent before completing the baseline questionnaire. A response rate of $68.8 \%$ was achieved for the telephone recruitment, and $43.4 \%$ for the postal strategy. Of those eligible for inclusion, $45.9 \%$ agreed to participate. However, only 1813 returned completed baseline questionnaires (33.4\% response rate overall).

\section{Data collection}

Although only baseline results are reported here, three data collections will be undertaken, each in the same season: (1) before participants move into their new home (baseline); (2) 12 months after moving; and (3) 2 years later.

\section{Measures}

The following were measured at baseline and will be repeated in future data collections:

\section{Physical activity}

Baseline physical activity was measured using NPAQ which measures the frequency and duration of usual recreational and transport-related walking and cycling undertaken within and outside the neighborhood (defined as a 15-min walk from home), as well as other moderate- and vigorous-intensity physical activity. The NPAQ is acceptably reliable (Giles-Corti et al., 2006). Participants were dichotomized according to each of the following indices: (1) $<150 \mathrm{~min} /$ week or $\geq 150 \mathrm{~min} /$ week of walking within the neighborhood (i.e., 10 - to 15 min walk from their home); (2) $<150 \mathrm{~min} /$ week or $\geq 150 \mathrm{~min} /$ week of total moderate physical activity. Participants were asked to wear a Yamax Digiwalker pedometer (SW-200-024) for 7 days and recorded steps in a diary before resetting the pedometer daily. Mean pedometer steps per day were computed.

Neighborhood characteristics that influenced choice of new neighborhood

Participants reported the importance of 21 factors influencing their choice of new housing development (see Table 4 for specific items) $(1=$ not important at all; $5=$ very important) and the estimated time it would take to walk from home to 22 businesses or recreational and transport-related facilities in their current neighborhood (Leslie et al., 2005; Saelens et al., 2003) (1=less than 5-min walk, $5=$ more than 20-min walk).

\section{Self-rated health, psychosocial factors and demographic variables}

Participants also self-reported their health status (overall health, weight status determined using height and weight and World Health Organization Body Mass Index (BMI) cut points (WHO, 2000), current smoking) and psychosocial factors including attitude towards being physically active and confidence to walk in the neighborhood (i.e., self-efficacy), and social support. Sociodemographic characteristics included gender, country of origin, marital status, the presence of children under 18 years at home; education level attained; work status; occupational status; household income; number of hours worked; total time spent traveling to and from work; and number of registered vehicles in household. Scales were created for individual cognitive variables comprising multiple items.

\section{Statistical analysis}

SPSS Version 12.0.1 was used to analyze the data. The internal consistency of each scale created for cognitive variables was satisfactory (Cronbach $\alpha \geq 0.85$ ). Pearson Chi-squared tests were used to examine the association between housing development type and categorical variables and one way analysis of variance used for continuous variables (using Dunnett T3 to assess significant differences between the developments). Logistic regression analyses were undertaken to determine if any differences observed between development types remained after adjustment for socio-demographic variables $(p<0.05)$.

\section{Results}

\section{Baseline demographic characteristics}

At baseline, $40.5 \%$ of RESIDE participants $(n=1813)$ were male and the average age was 40 years (Table 1 ). The majority was born in Australia, was married or living in a de facto relationship, had children at home and worked outside the home. Nearly one quarter were tertiary educated, over two in five were employed in a professional or managerial position, almost half worked more than $38 \mathrm{~h} /$ week (i.e., a full-time working week in Australia), $17.9 \%$ spent more than $1 \mathrm{~h} /$ day traveling to work and about a quarter lived in households with three or more motor vehicles and had an annual household income of less than $\$ 50,000$. Residents moving into HDs were more likely than others to report having two or more motor vehicles $(p=0.010)$, however, this difference attenuated after adjustment for other socio-demographic factors. There were no other socio-demographic differences by development type.

\section{Baseline health characteristics}

The majority of participants rated their health as good to excellent, although 53\% were overweight or obese and 14.2\% were smokers (Table 1). The only apparent health-related difference between the participants moving into each type of development related to weight status ( $p=0.052$ ). After adjusting for socio-demographic characteristics (not presented), this difference remained with those moving into HDs and CDs less likely than those moving into LDs to have an acceptable weight (OR 0.73; 95\% confidence interval (CI) $0.55-0.97$; OR 0.77 $95 \%$ CI $0.61-0.98$ respectively).

\section{Baseline psychosocial characteristics}

While the majority of participants had a positive attitude towards being physically active, less than one quarter were confident they could walk on most days of the week in their neighborhood during the next month (Table 2). Just over a quarter reported having regular social support for walking in the neighborhood (i.e., a friend, family member or both) and $10 \%$ personally walked with their dog at least five times per week. Confidence in walking daily in the neighborhood was the only psychosocial characteristic that differed between participants moving into different types of housing developments at baseline $(p=0.011)$. Those moving into LDs and CDs were more confident than those moving into HDs (reference category) that they could walk daily in their neighborhood and these differences remained after adjustment for socio-demographic characteristics (OR 1.35; 95\% CI 0.96-1.90; and OR 1.63; 95\% CI 1.19-2.23 respectively).

\section{Baseline perceptions of physical environmental characteristics}

Participants perceived that they had an average of 2.5 recreational and 6.3 transport-related destinations within a 15min walk from their baseline home address (Table 2). There 
Table 1

Baseline sociodemographic and health characteristics ${ }^{\text {a }}$ by type of development study participants are moving into

\begin{tabular}{|c|c|c|c|c|c|}
\hline \multirow[t]{3}{*}{ Characteristic } & \multicolumn{3}{|c|}{ Type of development moving into } & \multirow{3}{*}{$\begin{array}{l}\text { Total } \\
(n=1813)\end{array}$} & \multirow[t]{3}{*}{$p$ value } \\
\hline & Liveable & Hybrid & Conventional & & \\
\hline & $(n=538)$ & $(n=358)$ & $(n=917)$ & & \\
\hline \multicolumn{6}{|l|}{ Gender $(\%)$} \\
\hline Male & 39.6 & 40.8 & 40.9 & 40.5 & 0.880 \\
\hline Age (mean (SD)) & $40.2(12.4)$ & $39.6(11.7)$ & $40.0(11.6)$ & $40.0(11.9)$ & 0.699 \\
\hline \multicolumn{6}{|l|}{ Country of origin (\%) } \\
\hline Australia & 57.6 & 59.5 & 55.3 & 56.8 & \multirow[t]{3}{*}{0.661} \\
\hline Other & 41.8 & 40.2 & 44.3 & 42.7 & \\
\hline No response & 0.6 & 0.3 & 0.4 & 0.4 & \\
\hline \multicolumn{6}{|l|}{ Marital status (\%) } \\
\hline Married/De facto & 78.4 & 80.2 & 83.5 & 81.4 & \multirow[t]{4}{*}{0.185} \\
\hline Separated/Divorced/Widowed & 9.3 & 8.1 & 6.8 & 7.8 & \\
\hline Single & 12.3 & 11.7 & 9.5 & 10.8 & \\
\hline No response & 0.0 & 0.0 & 0.2 & 0.1 & \\
\hline \multicolumn{6}{|l|}{ Children at home (\%) } \\
\hline Yes & 64.3 & 65.1 & 69.1 & 66.9 & \multirow[t]{3}{*}{0.356} \\
\hline No & 31.8 & 30.7 & 27.2 & 29.2 & \\
\hline No response & 3.9 & 4.2 & 3.7 & 3.9 & \\
\hline \multicolumn{6}{|l|}{ Education (\%) } \\
\hline Secondary or less & 34.4 & 40.8 & 40.5 & 38.7 & \multirow[t]{5}{*}{0.120} \\
\hline Trade/Apprentice/Certificate & 37.9 & 33.5 & 37.5 & 36.8 & \\
\hline Bachelor or higher & 26.2 & 23.5 & 20.5 & 22.8 & \\
\hline Other & 1.5 & 2.0 & 1.2 & 1.4 & \\
\hline No response & & 0.3 & 0.3 & 0.2 & \\
\hline \multicolumn{6}{|l|}{ Work status (\%) } \\
\hline Work & 82.7 & 79.1 & 82.0 & 81.6 & 0.385 \\
\hline No work & 11.3 & 15.9 & 13.4 & 13.3 & \\
\hline Retired & 5.8 & 4.7 & 4.1 & 4.7 & \\
\hline No response & 0.2 & 0.3 & 0.4 & 0.3 & \\
\hline Occupational status (\%) & & & & & \\
\hline Management/Administration & 14.7 & 14.0 & 15.6 & 15.0 & 0.441 \\
\hline Professional & 30.1 & 26.5 & 26.3 & 27.5 & \\
\hline Blue collar & 18.6 & 16.2 & 16.2 & 16.9 & \\
\hline Clerical/Sales/Service/Other & 19.9 & 23.2 & 24.9 & 23.1 & \\
\hline Not in workforce & 16.0 & 18.7 & 15.7 & 16.4 & \\
\hline No response & 0.7 & 1.4 & 1.3 & 1.2 & \\
\hline Household income (\%) & & & & & \\
\hline$<\$ 49,999$ & 24.9 & 22.9 & 24.9 & 24.5 & 0.575 \\
\hline$\$ 50-69,999$ & 21.9 & 26.8 & 23.1 & 23.5 & \\
\hline$\$ 70-89,999$ & 20.3 & 20.9 & 23.2 & 21.9 & \\
\hline$\$ 90,000+$ & 27.0 & 23.2 & 23.3 & 24.4 & \\
\hline No response & 5.9 & 6.1 & 5.5 & 5.7 & \\
\hline No. of hours worked (\%) & & & & & \\
\hline Half time or less & 10.8 & 10.1 & 10.3 & 10.4 & 0.770 \\
\hline$>$ Half time to $38 \mathrm{~h} /$ week & 23.2 & 22.9 & 24.2 & 23.7 & \\
\hline$>38$ to $<60 \mathrm{~h} /$ week & 42.2 & 37.4 & 41.5 & 40.9 & \\
\hline $60+\mathrm{h} /$ week & 3.7 & 6.4 & 4.6 & 4.7 & \\
\hline Not in workforce & 16.0 & 18.7 & 15.7 & 16.4 & \\
\hline No response & 4.1 & 4.5 & 3.7 & 4.0 & \\
\hline Total time spent traveling to or $\mathrm{ft}$ & & & & & \\
\hline $1 / 2 \mathrm{~h}$ or less & 18.2 & 13.4 & 18.0 & 17.2 & 0.782 \\
\hline$>1 / 2-1 \mathrm{~h}$ & 24.5 & 21.5 & 22.9 & 23.1 & \\
\hline$>1$ & 17.5 & 18.7 & 17.8 & 17.9 & \\
\hline Not in workforce & 15.8 & 18.7 & 16.5 & 16.7 & \\
\hline Work from home & 3.0 & 2.8 & 2.3 & 2.6 & \\
\hline Total time spent traveling to or $\mathrm{fr}$ & & & & & \\
\hline Work in multiple locations & 20.1 & 23.7 & 21.5 & 21.5 & \\
\hline No response & 0.9 & 1.1 & 1.1 & 1.0 & \\
\hline No. of registered vehicles in hou & & & & & \\
\hline 1 Or less & 25.9 & 16.8 & 21.3 & 21.7 & 0.010 \\
\hline 2 & 50.8 & 54.2 & 52.7 & 52.4 & \\
\hline 3 Or more & 23.1 & 27.7 & 25.6 & 25.3 & \\
\hline No response & 0.2 & 1.4 & 0.4 & 0.6 & \\
\hline
\end{tabular}


Table 1 (continued)

\begin{tabular}{|c|c|c|c|c|c|}
\hline \multirow[t]{3}{*}{ Characteristic } & \multicolumn{3}{|c|}{ Type of development moving into } & \multirow{3}{*}{$\begin{array}{l}\text { Total } \\
(n=1813)\end{array}$} & \multirow[t]{3}{*}{$p$ value } \\
\hline & Liveable & Hybrid & Conventional & & \\
\hline & $(n=538)$ & $(n=358)$ & $(n=917)$ & & \\
\hline \multicolumn{6}{|l|}{ Self-rated health } \\
\hline Excellent & 14.5 & 14.0 & 14.1 & 14.2 & \multirow[t]{5}{*}{0.647} \\
\hline Very good & 35.9 & 35.9 & 38.7 & 37.3 & \\
\hline Good & 37.0 & 38.1 & 35.2 & 36.3 & \\
\hline Fair & 10.6 & 11.5 & 9.9 & 10.4 & \\
\hline Poor & 2.0 & 0.6 & 2.1 & 1.8 & \\
\hline \multicolumn{6}{|l|}{ Weight status } \\
\hline Acceptable & 51.8 & 43.6 & 45.3 & 46.9 & \multirow[t]{3}{*}{0.052} \\
\hline Overweight & 31.8 & 40.0 & 38.9 & 37.0 & \\
\hline Obese & 16.3 & 16.4 & 15.8 & 16.1 & \\
\hline \multicolumn{6}{|c|}{ Do you currently smoke cigarettes } \\
\hline Yes & 14.9 & 14.2 & 13.7 & 14.2 & \multirow[t]{2}{*}{0.923} \\
\hline No response & 1.3 & 1.1 & 1.6 & 1.4 & \\
\hline
\end{tabular}

${ }^{\text {a }}$ New Home Builders, Perth, Western Australia 2003-2005.

were no differences in perceived access to destinations in their baseline neighborhoods among participants moving into the different types of developments, including after adjustment for socio-demographic factors $(p>0.05)$.

\section{Baseline physical activity}

One half of participants walked for recreation and just over one third walked for transport within their neighborhood (Table 3), while $18 \%$ walked for recreation and $13 \%$ walked for transport outside their neighborhood. Of the total average minutes of walking reported (i.e., $128.4 \pm 159.8$ ), only $21 \%$ of mean minutes walked were transport-related within the neighborhood. Over one half $(53 \%)$ of mean minutes walked was recreational within the neighborhood and $27 \%$ was undertaken outside the neighborhood either for recreation or transport.

Overall, $42.6 \%$ met the guideline of the equivalent of at least $150 \mathrm{~min} /$ week of moderate activity and a third reported walking for $150 \mathrm{~min} /$ week or more.

The average number of steps taken per day was 8244.5 (SD 3756.5). The mean pedometer steps per day did not differ between the three groups. However, the unadjusted self-report results suggested that, on average, those moving into HDs undertook fewer minutes of walking for recreation compared with those moving into other types of developments. They were also less likely to report walking for at least $150 \mathrm{~min} /$ week and to be sufficiently active overall. Those moving into LDs also reported fewer mean minutes of walking for transport

Table 2

Baseline psychosocial characteristics and perceived characteristics ${ }^{\mathrm{a}}$ of local neighborhood by type of development study participants are moving into

\begin{tabular}{|c|c|c|c|c|c|}
\hline \multirow[t]{2}{*}{ Characteristic } & \multicolumn{3}{|c|}{ Type of development moving into } & \multirow[t]{2}{*}{ Total } & \multirow[t]{2}{*}{$p$ value } \\
\hline & Liveable & Hybrid & Conventional & & \\
\hline \multicolumn{6}{|l|}{ Attitude towards being physically active } \\
\hline Negative & 5.8 & 7.5 & 4.0 & 0.2 & \multirow[t]{3}{*}{0.073} \\
\hline Neutral/Mixed & 14.9 & 17.3 & 15.0 & 15.4 & \\
\hline Positive & 79.4 & 75.1 & 80.9 & 79.3 & \\
\hline \multicolumn{6}{|c|}{ Self-efficacy for walking on most days/week in neighborhood in next month } \\
\hline Not confident & 14.9 & 16.8 & 11.8 & 13.7 & \multirow[t]{3}{*}{0.011} \\
\hline Neither & 61.7 & 65.1 & 61.9 & 62.5 & \\
\hline Confident & 23.4 & 18.2 & 26.3 & 23.8 & \\
\hline \multicolumn{6}{|c|}{ Social support: walked with family member or friend $1-2$ times per week or more } \\
\hline Did not walk with family member or friend $1-2$ times per week & 60.2 & 66.2 & 61.0 & 61.8 & \multirow[t]{3}{*}{0.404} \\
\hline Walked with friend or family member & 11.2 & 10.3 & 11.1 & 11.0 & \\
\hline Walked with both & 28.6 & 23.5 & 27.9 & 27.2 & \\
\hline \multicolumn{6}{|c|}{ Number of times in usual week you personally walk the dog in neighborhood (\%) } \\
\hline Do not own dog & 58.4 & 53.4 & 54.8 & 55.6 & \multirow[t]{4}{*}{0.486} \\
\hline None & 9.3 & 11.7 & 9.7 & 10.0 & \\
\hline 1.4 times & 22.2 & 26.3 & 24.6 & 24.2 & \\
\hline 5 or more & 10.1 & 8.7 & 10.9 & 10.2 & \\
\hline \multicolumn{6}{|c|}{ Perceived number of recreational destinations within a 15 -min walk of home } \\
\hline Mean (SD) & $2.5(1.1)$ & $2.4(1.1)$ & $2.5(1.1)$ & $2.5(1.1)$ & 0.153 \\
\hline \multicolumn{6}{|l|}{ Perceived number of transport destinations within a 15-min walk of home } \\
\hline Mean (SD) & $6.6(4.2)$ & $6.2(4.1)$ & $6.3(4.1)$ & $6.3(4.2)$ & 0.270 \\
\hline
\end{tabular}

${ }^{\text {a }}$ New Home Builders, Perth, Western Australia 2003-2005. 
Table 3

Baseline usual physical activity behavior characteristics ${ }^{\text {a }}$ by type of development study participants are moving into

\begin{tabular}{|c|c|c|c|c|c|}
\hline \multirow{2}{*}{$\begin{array}{l}\text { Usual physical } \\
\text { activity behavior }\end{array}$} & \multicolumn{3}{|c|}{ Type of development moving into } & \multirow[t]{2}{*}{ Total } & \multirow[t]{2}{*}{$p$ value } \\
\hline & Liveable & Hybrid & Conventional & & \\
\hline \multicolumn{6}{|c|}{ Walking within neighborhood } \\
\hline \multicolumn{6}{|l|}{ Recreation } \\
\hline Usually walk (\%) & 52.0 & 48.9 & 54.3 & 52.6 & 0.210 \\
\hline Mean min/week (SD) & $70.6(104.3)$ & $55.94(86.8)^{\mathrm{b}}$ & $70.3(98.0)$ & $67.6(98.0)$ & 0.043 \\
\hline \multicolumn{6}{|l|}{ Transport } \\
\hline Usually walk (\%) & 36.8 & 37.2 & 35.2 & 36.1 & 0.547 \\
\hline Mean min/week (SD) & $28.9(63.0)$ & $21.11(37.1)$ & $26.9(60.6)$ & $26.3(57.6)$ & 0.132 \\
\hline \multicolumn{6}{|c|}{ Walking outside neighborhood } \\
\hline \multicolumn{6}{|l|}{ Recreation } \\
\hline Usually walk (\%) & 17.8 & 15.1 & 18.6 & 17.7 & 0.344 \\
\hline Mean min/week (SD) & $19.7(55.2)$ & $17.12(55.0)$ & $22.2(68.2)$ & $20.4(61.6)$ & \\
\hline \multicolumn{6}{|l|}{ Transport } \\
\hline Usually walk (\%) & 11.9 & 13.7 & 13.8 & 13.2 & 0.324 \\
\hline Mean min/week (SD) & $9.7(44.1)^{\mathrm{c}}$ & $12.67(39.2)$ & $17.2(68.6)$ & $14.1(57.1)$ & 0.048 \\
\hline \multicolumn{6}{|l|}{ Total walking } \\
\hline$\geq 150 \mathrm{~min} /$ week $(\%)$ & 34.8 & 28.5 & 35.8 & 34.0 & 0.044 \\
\hline Mean min/week (SD) & $128.9(155.7)$ & $106.84(134.5)^{\mathrm{d}}$ & $136.5(170.3)$ & $128.4(159.8)$ & 0.012 \\
\hline \multicolumn{6}{|c|}{ Usual overall physical activity behavior (\%) } \\
\hline Sufficiently active ${ }^{\mathrm{e}}$ & 44.6 & 35.2 & 44.4 & 42.6 & 0.006 \\
\hline \multicolumn{6}{|c|}{ Objective measurement of total walking (pedometer) } \\
\hline Mean steps/day (SD) & $8274.4(3871.9)$ & $7957.9(3657.7)$ & $8340.9(3724.9)$ & $8244.5(3756.5)$ & 0.260 \\
\hline
\end{tabular}

Table 4

Factors (in overall order of importance) that influenced choice of new housing development by type of development study participants are moving into ${ }^{\text {a }}$

\begin{tabular}{|c|c|c|c|c|c|}
\hline \multirow[t]{4}{*}{ Development characteristic } & \multicolumn{3}{|c|}{ Type of development moving to } & \multirow{2}{*}{$\begin{array}{l}\text { Total } \\
\%\end{array}$} & \multirow[t]{4}{*}{$p$ value } \\
\hline & Liveable & Hybrid & Conventional & & \\
\hline & $\%$ & $\%$ & $\%$ & \multirow[b]{2}{*}{$(n=1813)$} & \\
\hline & $(n=538)$ & $(n=358)$ & $(n=917)$ & & \\
\hline Affordability/Value & 86.7 & 86.0 & 86.1 & 86.3 & 0.942 \\
\hline Safety from crime & 86.7 & 88.3 & 84.3 & 85.8 & 0.141 \\
\hline Closeness to parks & 69.1 & 68.2 & 65.1 & 66.9 & 0.258 \\
\hline Designed as safe for children & 65.4 & 68.2 & 65.6 & 66.0 & 0.633 \\
\hline Streets designed minimize traffic & 59.7 & 64.5 & 63.4 & 62.5 & 0.263 \\
\hline Choice lot sizes and housing types & 59.6 & 57.0 & 56.9 & 57.7 & 0.594 \\
\hline Desire nearby shops/services & 63.5 & 58.1 & 53.2 & 57.2 & 0.001 \\
\hline Ease of walking & 59.7 & 58.1 & 53.4 & 56.2 & 0.048 \\
\hline Sense of community & 64.6 & 57.8 & 55.0 & 58.4 & 0.002 \\
\hline Streets designed safer for pedestrians/cyclists & 56.9 & 55.9 & 51.5 & 54.0 & 0.096 \\
\hline Easy find way around neighborhood & 49.8 & 52.8 & 51.1 & 51.1 & 0.682 \\
\hline Streets have footpaths & 55.8 & 54.7 & 46.7 & 51.0 & 0.002 \\
\hline Access to freeway & 51.9 & 52.5 & 48.0 & 50.0 & 0.207 \\
\hline Closeness to recreational facilities & 52.1 & 50.0 & 46.4 & 48.8 & 0.105 \\
\hline Closeness to variety of parks & 52.4 & 42.7 & 43.8 & 46.2 & 0.002 \\
\hline Closeness to school & 39.9 & 43.9 & 43.2 & 42.3 & 0.385 \\
\hline Closeness to beach & 48.5 & 22.6 & 35.6 & 36.9 & $<0.0001$ \\
\hline Closeness to transit & 41.4 & 39.1 & 32.5 & 36.4 & 0.002 \\
\hline Ease of cycling & 37.3 & 38.5 & 30.1 & 33.9 & 0.002 \\
\hline Closeness to jobs & 30.3 & 33.8 & 32.7 & 32.2 & 0.506 \\
\hline Closeness to place study & 9.9 & 13.7 & 11.7 & 11.6 & 0.224 \\
\hline
\end{tabular}

${ }^{\mathrm{a}}$ New Home Builders, Perth, Western Australia 2003-2005. 
outside the neighborhood compared with those moving into CDs.

After adjustment for socio-demographic variables (not shown in table), those moving into CDs remained significantly more likely than those moving into HDs (reference category) to meet the threshold for both sufficient walking and physical activity (OR 1.41; 95\% CI 1.07-1.86; OR 1.31; 95\% CI $1.02-$ 1.69 respectively). The odds of achieving sufficient physical activity were also higher for those moving into LDs compared with HDs (OR 1.32; 95\% CI 1.00-1.75), although for walking, the adjusted difference did not reach statistical significance $(\mathrm{OR}=1.32,95 \% \mathrm{CI}=0.98-1.79)$. There was no evidence of any differences in the activity levels of participants moving into LDs and CDs $(p>0.05)$.

\section{Factors that influenced choice of new housing development}

The perceived importance of 21 factors in influencing choice of new housing development was assessed (Table 4). The most commonly cited reasons, irrespective of housing development chosen, were affordability and safety from crime, followed by closeness to parks, designed as safe for children and streets designed to minimize traffic.

More than half the respondents also cited factors considered to make a housing development more walkable including a desire to be nearby shops/services, ease of walking, streets designed safer for pedestrians and cyclists, and having streets with footpaths and a sense of community. The perceived importance of these latter factors differed significantly between participants moving into different developments. Those moving into LDs were more likely to rate as important the desire to be near shops/services, sense of community, closeness to a variety of parks, and closeness to the beach. Similarly, compared with those moving to CDs, more residents moving into LDs and HDs rated important the presence of footpaths, ease of walking, ease of cycling and proximity to transit.

After adjustment for socio-demographic characteristics (not shown in table), participants moving into CDs remained significantly less likely than those moving into LDs (reference category) to rate as important a desire to be nearby shops and services (OR $0.65 ; 95 \%$ CI $0.52-0.82$ ); ease of walking (OR 0.76 ; $95 \%$ CI $0.60-0.95$ ); sense of community (OR $0.64 ; 95 \%$ CI $0.51-0.81$ ); the presence of footpaths (OR $0.65 ; 95 \%$ CI $0.52-0.82$ ); closeness to parks (OR 0.69 ; $95 \%$ CI $0.55-0.86$ ); closeness to beach (OR $0.59 ; 95 \%$ CI $0.47-0.73$ ); closeness to transit (OR 0.59; 95\% CI 0.47-0.73); and ease of cycling (OR $0.69 ; 95 \%$ CI $0.54-0.87)$. Conversely, the only differences in perceived importance between those moving into HDs compared with LDs related to the development's sense of community (OR $0.73 ; 95 \%$ CI $0.55-0.97)$; access to a variety of parks (OR 0.66; 95\% CI 0.50-0.87); and access to beach (OR 0.30; $95 \%$ CI $0.22-41)$.

\section{Discussion}

As a quasi-experimental longitudinal evaluation of a pedestrian-friendly state government subdivision design code,
RESIDE is unique. For similar future studies, the baseline results highlight the potential importance of measuring the type (i.e., transport and recreational related) and location of walking. RESIDE's longitudinal design enables self-selection to be studied. This is also important because people moving into LDs reported that a preference for more walkable neighborhoods contributed to their choice of new housing development. The study design permits the impact of neighborhood preference on subsequent behavior to be studied.

Importantly, there was little difference in the baseline walking behavior of those moving into LDs and CDs. Those moving into HDs appeared less likely to walk for recreation, were less active overall and were not confident they could walk daily when faced with competing demands (Bandura, 1982). As few other demographic or socioeconomic characteristics varied between participants moving into different housing developments, it is possible that the results are explained by 'coastal effect' whereby those living near the ocean are more active than those living inland (Bauman et al., 1999). Distance from the ocean was used to match developments in the study design stage, however, unlike other developments, nearly all HDs were located inland. It is possible that even people choosing to live further from the coast are less active (Bauman et al., 1999) and that self-selection is indeed present. Changes in behavior in response to any changes in urban form, attitudes and lifestyles will be monitored once participants move into their new homes.

At baseline the majority of walking undertaken by RESIDE participants was recreational and within the neighborhood: only $20 \%$ of the mean walking time was transport related. A low mean number of local transport destinations (6.3) within walking distance was reported, indicating that by international standards, RESIDE participated lived in low walkable neighborhoods (Hoehner et al., 2005). Moreover, nearly 30\% of reported walking was undertaken outside the neighborhood. In a small pilot study ( $n=35$ ), Rodriguez et al. (2005) used GPS equipment to measure activity undertaken within and outside the neighborhood and found that while there were fewer bouts of activity within the neighborhood, these bouts were longer, contributing to more moderate and vigorous activity. Higher levels of within neighborhood activity were associated with neighborhood walkability.

Nevertheless, in most environmental studies, although correlates are measured at the 'neighborhood' level, behavioral context is ignored as is the type of walking. There is growing recognition that neighborhood correlates of recreational and transport-related walking differ (Transportation Research Board, 2005). More is known about the correlates of the latter than the former. Thus, studies that ignore the type (i.e., walking for transport or recreation) and location of walking (within or outside the neighborhood) may underestimate the potential impact of relevant environmental correlates due to a mismatch between outcome and predictor variables (Giles-Corti et al., 2006). Moreover, studies of natural experiments will benefit from measuring specific behaviors and contexts to assess: (1) behavioral changes; (2) whether substitution has taken place (i.e., more local walking but no more walking or physical 
activity overall) (Merom et al., 2003; Rodriguez et al., 2005); and (3) whether participation in local walking aids behavioral maintenance over time.

Affordability was the key driver of residential location choice, followed by a desire to live in a 'safe' neighborhood. Nevertheless, compared with those moving into other developments - particularly CDs - more people moving into LDs claimed that aspects of their new development's walkability (e.g., proximity of shops and services, the presence of footpaths) drove their decision. A major concern for environmental studies is that residents with a positive predisposition would walk, cycle or use transit irrespective of land form (Handy et al., 2005). Thus, the extent to which this apparent preference translates into more walking will also be monitored in follow-up surveys of RESIDE participants.

Future research could monitor urban form preferences (Frank et al., 2007) to provide policy makers and property developers evidence of any latent demand for medium to high density mixed-use housing development. In this study, more than half surveyed rated aspects of neighborhood walkability as important drivers of residential choice. In the US, up to $25 \%$ of residents are said to be mismatched in terms of their residential development preferences (Cervero and Duncan, 2002). This underscores the value of providing diversity in housing stock - particularly affordable, compact and walkable developments along transit routes - to meet current and future demands for pedestrian and transit-friendly neighborhoods that require less dependence on motor vehicles for transportation (Cervero and Duncan, 2002; Schwanen and Mokhtarian, 2005).

\section{Study limitations}

At baseline, study participants reported access to few local destinations suggesting that they live in low walkable: neighborhoods. This may explain the low level of local transportrelated walking, yet as a natural experiment, this could not be controlled. The response rate of $33 \%$ is somewhat low, although not surprising given the study requirements. However, minimizing attrition is now the priority. Our protocol involves sending postcards, warning study participants to expect the questionnaire (sent with a personalized letter and nominal, yet tangible, incentives (e.g., a tea bag, vouchers for a complimentary video and discount at a bicycle shop; plus and a prize draw for a weekend-away package)). Each study participant receives six follow-up contacts (post-cards, letters and telephone calls) before being considered lost-to-follow-up and contact is maintained through a 6-monthly newsletter about the study's progress (Dilman, 2000).

\section{Conclusion}

The baseline results of RESIDE suggest that it is desirable to incorporate behavior and context-specific measures in studies of urban form and walking. We have demonstrated the feasibility of designing a longitudinal quasi-experimental study on the impact of neighborhood design on and physical activity and that issues related to self-selection are present and need to be considered. The baseline results underscore the value of longitudinal study designs to monitor changes to behavior in response to changes in lifestyle, attitudes, urban form while adjusting for baseline residential location preferences.

\section{Acknowledgments}

Funding from the Western Australian Health Promotion Foundation (Healthway) is also gratefully acknowledged (Grant No. 11828). The first author is supported by a NHMRC/NHF Career Development Award (Grant No. 254688) and the third, by a VicHealth Public Health Fellowship (2004 0536). Sponsors of our incentives are also acknowledged (VideoEzy, Bike Force South Perth, Atrium Hotel, Mandurah Gates Resort and Madura Tea).

\section{References}

Bagley, M., Mokhtarian, P., 2002. The impact of residential neighborhood type on travel behavior: a structural equations modeling approach. Ann. Reg. Sci. 36, 279-297.

Bandura, A., 1982. Self-efficacy mechanism in human agency. Am. Psychol. 37, $122-147$.

Bauman, A., Smith, B., Stoker, L., Bellew, B., Booth, M., 1999. Geographical influences upon physical activity participation: evidence of a 'coastal effect'. Aust. N. Z. J. Public Health 23, 322-324.

Cervero, R., Duncan, M., 2002. Residential self selection and rail commuting: a nested logit analysis. University of California Transportation Center, Berkeley, California.

Dilman, D.A., 2000. Mail and Internet surveys. The tailored design method. John Wiley and Sons, Inc, New York.

Ewing, R., Schmid, T., Killingsworth, R., Zlot, A., Raudenbush, S., 2003. Relationship between urban sprawl and physical activity, obesity and morbidity. Am. J. Health Promot. 18, 47-57.

Frank, L., Engelke, P., Schmid, T., 2003. Health and community design. The impact of the built environment on physical activity. Island Press, Washington.

Frank, L.D., Saelens, B.E., Powell, K.E., Chapman, J.E., 2007. Stepping towards causation: do built environments or neighborhood and travel preferences explain physical activity, driving, and obesity? Soc. Sci. Med.

Giles-Corti, B., Timperio, A., Bull, F., Pikora, T., 2005. Understanding physical activity environmental correlates: increased specificity for ecological models. Exerc. Sport Sci. Rev. 33, 175-181.

Giles-Corti, B., Timperio, A., Cutt, H., et al., 2006. Development of a reliable measure of walking within and outside the local neighborhood: RESIDE's Neighborhood Physical Activity Questionnaire. Prev. Med. 42 (6), 455-459.

Hall, K., Porterfield, G., 2000. Community by design: new urbanism for suburbs and small communities. McGraw Hill, Osborne. 2001.

Handy, S., Clifton, K., 2001. Local shopping as a strategy for reducing automobile travel. Transportation 28, 317-346.

Handy, S., Cao, X.Y., Mokhtarian, P., 2005. Correlation or causality between the built environment and travel behavior? Evidence from Northern California. Transp. Res., Part D Transp. Environ. 10, 427-444.

Hoehner, C.M., Raminez, L.K.B., Elliott, M.B., Handy, S.L., Brownson, R.C., 2005. Perceived and objective environmental measures and physical activity among urban adults. Am. J. Prev. Med. 28 (2S2), 105-116.

Humpel, N., Owen, N., Iverson, D., Leslie, E., Bauman, A., 2004a. Perceived environment attributes, residential location, and walking for particular purposes. Am. J. Prev. Med. 26, 119-125.

Humpel, N., Owen, N., Leslie, E., Marshall, A.L., Bauman, A.E., Sallis, J.F., 2004 b. Associations of location and perceived environmental attributes with walking in neighborhoods. Am. J. Health Promot. 18, 239-242. 
Jackson, R., 2003. The impact of the built environment on health: an emerging field. Am. J. Public Health 93, 1382-1383.

Krizek, K.J., 2000. Pretest-posttest strategy for researching neighborhood-scale urban form and travel behavior. Transp. Res. Rec. 48-55.

Krizek, K.J., 2003. Residential relocation and changes in urban travel-does neighborhood-scale urban form matter? J. Am. Plan. Assoc. 69, 265-281.

Leslie, E., Saelens, B., Frank, L., et al., 2005. Residents' perceptions of walkability attributes in objectively different neighbourhoods: a pilot study. Health Place 227-236.

Merom, D., Bauman, A., Vita, P., Close, G., 2003. An environmental intervention to promote walking and cycling - The impact of a newly constructed Rail Trail in Western Sydney. Prev. Med. 36 (2), 235-242.

Newman, P., Kenworthy, J., 1989. Sustainability and cities: overcoming automobile dependence: an international sourcebook. Gower, Aldershot, England.
Rodriguez, D.A., Brown, A.L., Troped, P.J., 2005. Portable global positioning units to complement accelerometry-based physical activity monitors. Med. Sci. Sports Exerc. 37 (11 Suppl), S572-S581.

Saelens, B.E., Sallis, J.F., Black, J.B., Chen, D., 2003. Neighborhood-based differences in physical activity: an environment scale evaluation. Am. J. Publ. Health 93, 1552-1558.

Schwanen, T., Mokhtarian, P., 2005. What affects commute mode choice: neighborhood physical structure ore preferences towards neighborhoods? J. Transp. Geogr. 13, 83-99.

Transportation Research Board, 2005. Does the built environment influence physical activity? Examining the evidence. TRB, Washington, DC.

Western Australian Planning Commission, 2000. Liveable neighbourhoods Western Australian Planning Commission, Perth.

WHO, 2000. Obesity. Preventing and managing the global epidemic. WHO Technical Report Series, vol. 894. WHO, Geneva. 